\title{
Summary and highlights
}

\section{G. Alimonti}

INFN, Sezione di Milano and Dipartimento di Fisica, Università di Milano Via Celoria 16, 20133 Milano, Italy

Summary. - Energy means development, and access to energy and electricity should be possible for everyone. The energy challenge for the years to come is to have a sustainable energy supply and after the week spent in Varenna it is clear that "sustainable" cannot be identified with green gas emission reduction only: it has to be an energy supply system respectful of the environment and the humankind, able to provide reliable and affordable energy to the whole world population. This is definitely not an easy challenge: no single energy technology will suffice to safeguard our future and any possible solution has to be exploited at its best, from renewable to nuclear energy, from clean fossil fuels to biofuels. Last but not least, it is the energy efficiency that, given the actual technology, may give the most important and immediate contribution to this challenge. Meanwhile researchers must examine a broad range of options and develop different kinds of technologies: only new investments on $\mathrm{R} \& \mathrm{D}$ can allow to meet the growing demand for energy in a responsible, equitable, and sustainable way.

"Like food, air, and water, energy is essential to human existence. The hopes of billions for a better life depend on plentiful and accessible sources of energy. One of the central challenges of the 21st century is to ensure a sustainable energy supply for the world's people and its economy".

These are the words by E. De Sanctis, in his lecture on energy and scientific communication, opening the great week we spent together in Varenna learning about energy. 
But what does "sustainable energy supply" mean?

In the introductory presentation we have been reminded that "Energy inequalities pose increasingly severe environmental and human challenges:

- In a world characterized by strikingly unequal rates of energy consumption it will be difficult to develop collectively rational responses to global climate threats.

- Energy inequalities increase the potential for resource-based geopolitical conflicts.

- They also foster unhealthy consumption habits throughout the developed world, while preventing entire generations of men, women, and children in the developing world from fully realizing their potential as citizens of the modern world".

Moreover in the last ten years, with a world population growth of $12 \%$, there has been a primary energy demand increase of $20 \%$, becoming $30 \%$ in terms of electricity, and these numbers are going to become more and more important by the middle of the century when the world population is expected to be around 9 billion people, with a $28 \%$ increase.

M. Ricotti, in his lectures on nuclear energy, also reminded us that nowadays about 1.5 billion people do not have access to electricity and almost 3 billions do not have clean cooking facilities being thus forced to use biomass for domestic needs causing, according to WHO (World Health Organization), more than 1 million pollution deaths per year.

Energy means development and access to energy and electricity should be possible for everyone.

We thus found out that the energy challenge cannot be identified with $\mathrm{CO}_{2}$ reduction only: the reduction of pollutants like fine particulate, carbon monoxide, sulfur oxides and other compounds is also important together with fulfilling the energy needs of the whole world population.

We learned that "sustainable energy supply" has a broader and maybe slightly different meaning than what we are used to: maybe something closer to an energy supply system respectful of the environment and the humankind, able to provide reliable and affordable energy to the world population even when fossil fuels will not be so easily available any more.

This is definitely not an easy challenge!

It may be interesting and instructive to see that a revolutionary idea and not a new energy source solved a similar problem in the past, when the growing society energy needs could not be satisfied any more by the original renewable energies, wind, solar and biomass: the steam engine, able to transform thermal energy into mechanical energy, and soon after in electricity, entering all the different sectors of our life with transport, civilian or industrial applications.

Figure 1 shows that since ancient times there have been such trials; recent years rushing technological developments allowed us to build larger and larger thermoelectric power stations, nowadays with about $1 \mathrm{GW}$ power and almost $60 \%$ thermoelectric efficiency, as brought to our attention by M. Gaderer in his lectures on fossil power plants, able to 


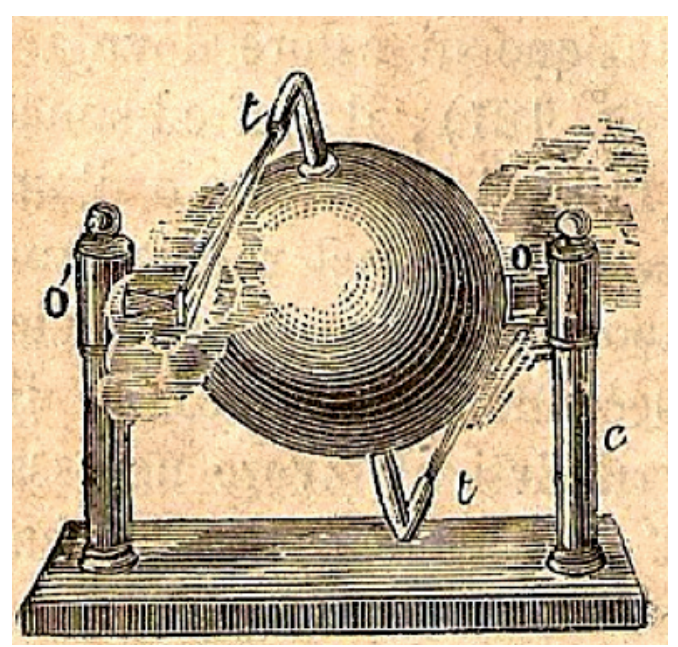

Fig. 1. - An illustration of one of the first trials by Heron of Alexandria to convert heat to mechanical energy.

produce plenty of energy, fed and distributed in extended and sophisticated power grids, a remarkable engineering success shown in fig. 2, that need complex control room to be maintained in uninterrupted equilibrium.

\section{Interconnected power grids are a remarkable engineering success and achievement of our societies}

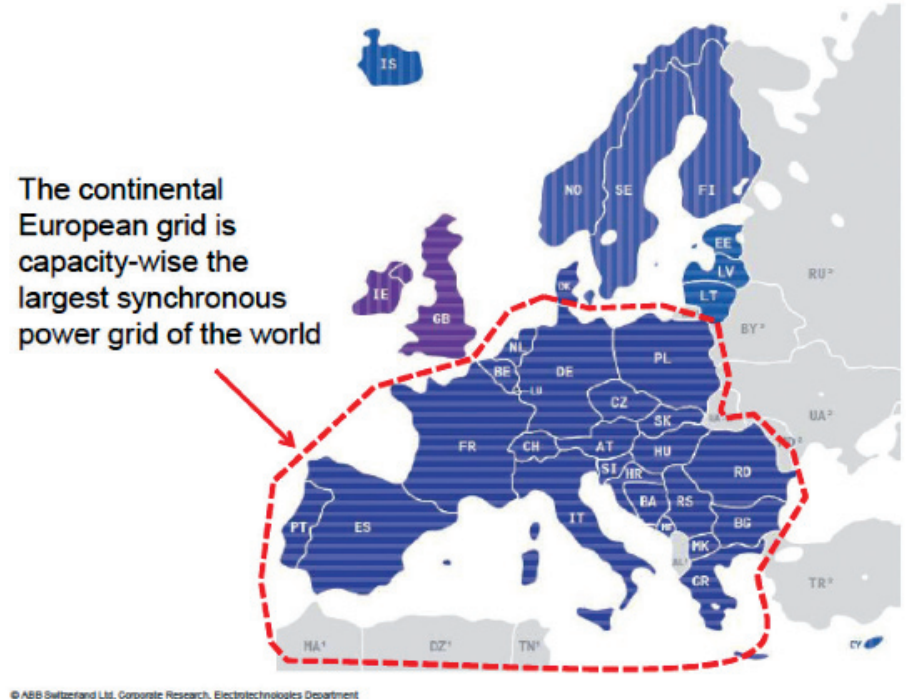

Fig. 2. - Power grids are a remarkable achievement of our society. 


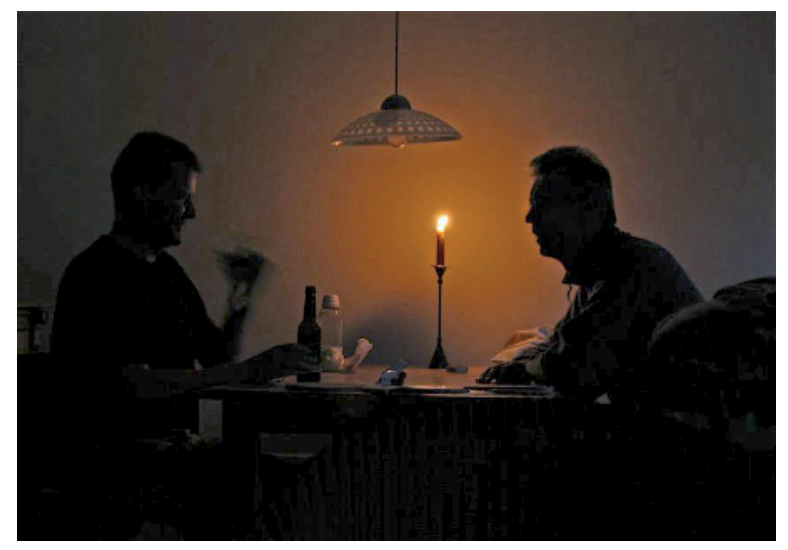

Fig. 3. - Turning light off at our wish is a privilege allowed by a SAIDI (System Average Interruption Duration Index) of about 15-60 minutes per year, $0.005 \%$ of the time in Europe and US.

This all happens without us even noticing, providing electricity with very high reliability, as explained by C. Ohler in his lectures on electric power systems, and giving us the privilege... (see fig. 3) to turn light off at our wish!

But the whole system has the sustainability limits mentioned above and it is certainly not available for everyone in the world.

What can then be done?

It immediately came out clearly that nowadays a single answer does not exist, but a whole set of possible solutions that have to be exploited at their best: renewable energy sources are certainly among these.

The Sun is the source where all the renewable energies come from: it is thus natural to look first at the possible exploitation of this energy source.

The radiating energy coming from the Sun hitting our planet is about 10000 times the global energy consumption: it would be enough to cover a small part of the Sahara desert with photovoltaic (PV) modules to satisfy the world energy demand. Despite this evaluation, nowadays PV energy is only about $0.04 \%$ of the global energy supply, mainly for both technological and economical limits.

From a technological point of view, PV energy, like wind energy that will be dealt with later, is an intermittent and not always predictable source of energy and this may cause dangerous instabilities to the delicate and complex power distribution grid system that we have seen above: there is a stringent limit on intermittent power that can be grid connected.

Moreover this kind of sources produce energy when the sun is shining or the wind is blowing that is not always when the energy is needed: excluding the hydro pumping storage, that represents a small power with strong geographical limitations, large scale energy storage is not possible and this is an important limit to the diffusion of these intermittent energy sources. 


\section{Thermoelectric Energy Storage}

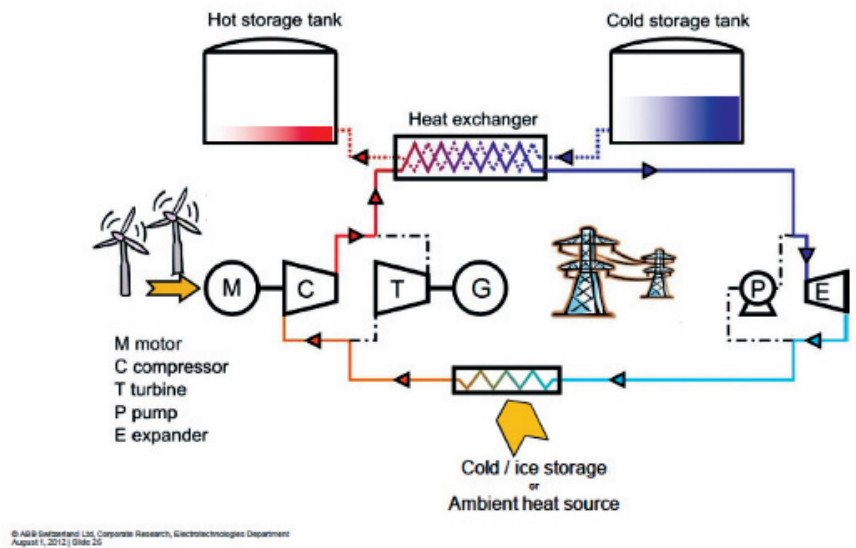

Fig. 4. - ETES (Electro-Thermal Energy Storage) is a potential solution for large capacity electricity storage.

To overcome this limit, it is necessary to configure an important R\&D strategy towards smart grids helped by innovative storage energy systems, like, for example, the thermoelectric energy storage presented by C. Ohler in his lecture on electric power systems, and shown in fig. 4.

This system would allow interesting storage and transformation efficiencies although with an unavoidable energy cost increase.

And here we come to the second PV limit: the high cost of the energy produced by this source, that is probably the most expensive among the renewable energy sources.

To lower the generation costs of the present PV technology, called first generation technology, down to a level competitive with the standard power generation sources, like coal, gas or nuclear, there are two possible strategies, as pointed out by P. Lagoudakis in his lectures on hybrid nanophotonics, showing a famous plot by M. Green, a historical researcher in this field, reproduced in fig. 5: either PV module costs are dramatically cut, although loosing a little bit of efficiency (e.g., thin film devices), or a much higher efficiency is reached, keeping the unavoidable cost increase to a reasonable level (e.g., concentrated PV).

The first strategy is followed by the R\&D shown by D.S. Wiersma in his talk "Trapping the light fantastic", where a simple and cost effective surface process enhances the absorbed light that is later converted to electricity. The second strategy is followed by the R\&D shown by P. Antonini in his talk on concentrated photovoltaics and presented in fig. 6: triple junction solar cells, able to convert a larger part of the solar light spectrum, have been built in different laboratories reaching a record conversion efficiency of $43.5 \%$. Manufacturing costs are obviously much higher than a normal silicon PV cell, but when the triple junction cell is exploited in a concentration PV system, the Levelized Cost Of Energy (LCOE, the important parameter to consider for cost considerations), may come out to be competitive. 


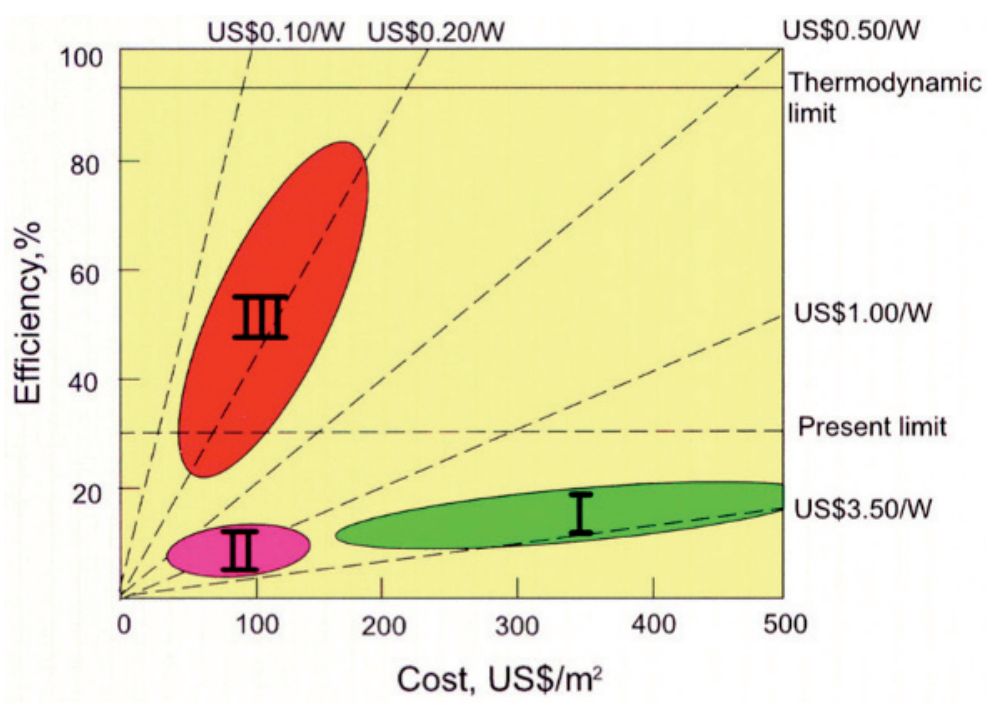

Fig. 5. - Famous plot by M. Green presenting possible developments of photovoltaic generations to reach economic competitiveness.

$\mathrm{R} \& \mathrm{D}$ is thus fundamental also for this recent and very promising energy production technology: P. Lagoudakis showed us that modern physics and nanotechnology should now (re)consider the photovoltaic problem with new innovative solutions. There is plenty of space for basic and advanced nanostructures research for both light harvesting and emitting devices. The goal is to exploit high absorption, color tunability, high quantum

\section{Concentrated PhotoVoltaics (CPV): is it a real opportunity?}

\section{P. Antonini

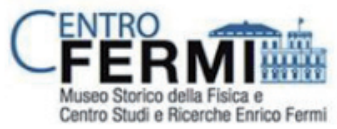

Varenna School on energy, $4^{\text {th }}$ August, 2012
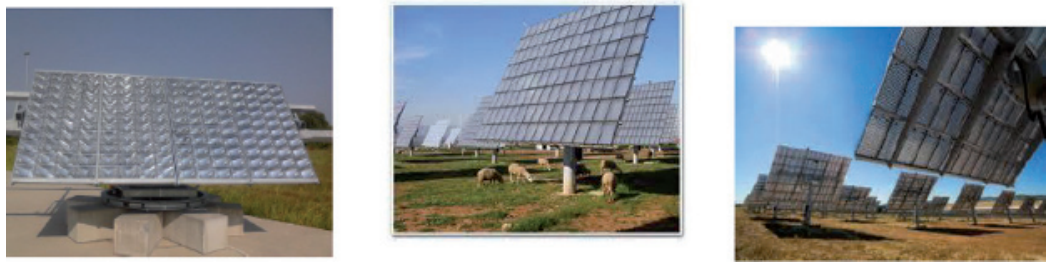

Fig. 6. - CPV is an opportunity to exploit the high triple-junction conversion efficiency. 


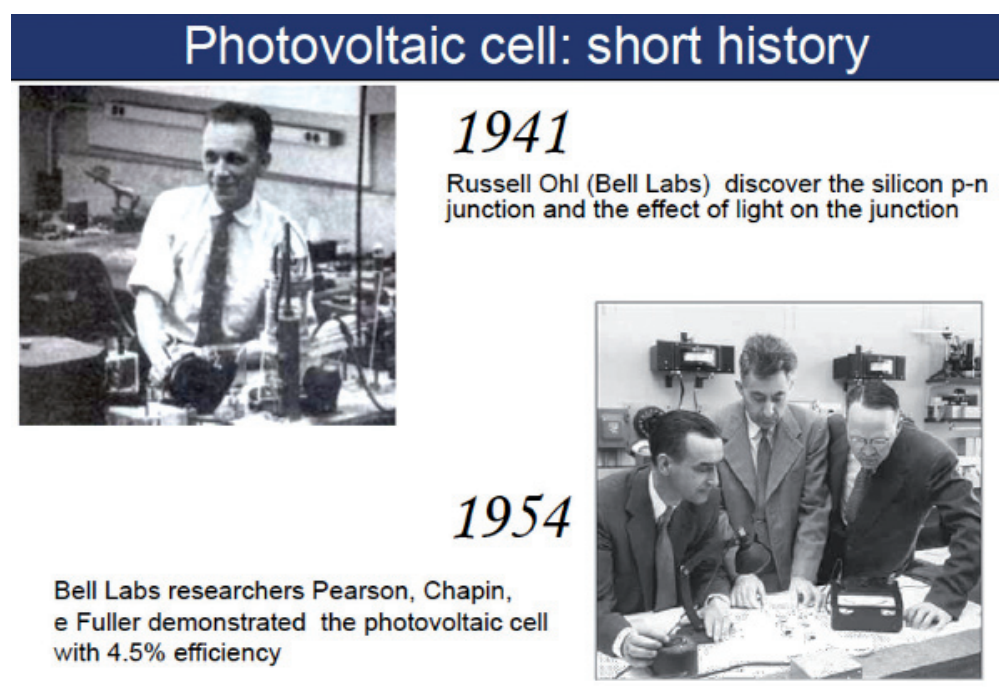

Fig. 7. - Important steps in the photovoltaic cell history.

yield and low cost of colloidal quantum dots with the typical high carrier mobility of epitaxial semiconductors, coupled by a non-radiative energy transfer.

A historic connection between two energy sources that are often seen as one against the other is inspired by the slide shown in fig. 7 and presented by P. Lagoudakis: PV and nuclear energy.

Russel Ohl (Bell Labs) discovered the silicon $p$ - $n$ junction and the effect of light on the junction in 1941; it is impossible to forget that one year later, on December 2, 1942, E. Fermi turned the CP-1 on, the world first human-made nuclear reactor

Again, Bell Labs researchers Pearson, Chapin and Fuller demonstrated the photovoltaic cell with $4.5 \%$ efficiency in 1954, showing to mankind a potential new energy source; one year later in Geneva the famous "Atoms for peace" conference took place, where classified documents on nuclear energy were disclosed to allow the exploitation of a new energy source. For different reasons, both these technologies still need important R\&D programs.

Wind energy, with $239 \mathrm{GW}$ at the end of 2011, has the highest installed power among the electricity producing renewable sources, excluding the hydropower, as illustrated by J.H. Wagner in his lectures on wind energy, and this is due to its reasonably low $\mathrm{kWh}$ production cost, dependent on the production site, but being almost competitive with standard technologies. Nevertheless the above mentioned intermittency problems, the material resistance and the system lifetime are important limits.

For these reasons, also for this technology R\&D plays and will play in the future an important role. Developments are expected in several fields like offshore installations, with even more challenging requests, and new wind technologies like those described for instance by M. Milanese in his talk: very large high-flying kites linked to ground by high resistance ropes, likely capable to exploit stronger, more reliable and predictable winds. 
Transportation is a very peculiar sector: while heat and electricity may be generated starting from several different sources, transportation basically relies on oil only.

A possible sustainable solution, according to the definition given at the beginning, could be offered by biofuels being produced by renewable biomass and able to be used in conventional internal combustion engines with small and simple changes.

Are we sure that biofuels offer a sustainable solution? S. Johansson, in her lectures on biofuel production, gave us some data that may help in finding an answer. First of all it should not be forgotten that modern agriculture needs several processings, fertilizers, agricultural machinery, transformation and transportation of the products, that require a lot of energy, most of the times coming from fossil fuels. Studies show that, depending on the manufacturing steps, the output energy from some biofuel is very similar, if not less than, the input energy used along the whole production process: that makes the biofuel under consideration definitely not convenient both from the economical and the environmental point of view.

Furthermore biofuels, coming from agricultural fields being normally used for food production, may jeopardize food security: we have been told that the maximum theoretical limit from the present agriculture to produce biofuels, without directly affecting food security, is approximately $8000 \mathrm{TWh}$, that is just about $5 \%$ of the global energy consumption.

The conclusion by S. Johansson is that the edible production should not be used for biofuels; a limited amount of biofuels may be obtainable, however it is not evident that this would not affect food security.

Also in this sector, hopes are thus based on R\&D strategies: second-generation biofuels, advanced processes that need less energy to make biofuels out of food production waste or even from algae or bacteria intentionally developed to maximize the production, are the state of the art R\&D programs that have the chances to find a more sustainable solution.

Coming back to transportation, the electric car seems to be an option becoming more and more interesting: it would limit pollution in towns with dense road traffic and, maybe more important, it would allow all the electricity producing energy sources to enter the transportation sector.

Recent battery developments, particularly the lithium ion batteries, allowed the electricity to enter the automotive sector even though high costs and low mileage are still stringent limits and further developments are needed: also in this sector an R\&D strategy is fundamental. L.J.F. Hermans in his lecture on energy and transportation, showed us that it is very difficult to beat internal combustion engines because of the high energy and power density they have, as shown in fig. 8 .

Fuel cells have gone through important developments in recent years but, according to A. McEvoy in his talk on electrochemistry, this technology is and will be left out of transportation for several more years, not allowing hydrogen to enter the automotive sector as wished by many people. Different use of this technology will be more likely: combined heat and power (CHP) generation, where not only the electricity, but also the heat produced by the process is used, could be an example. 

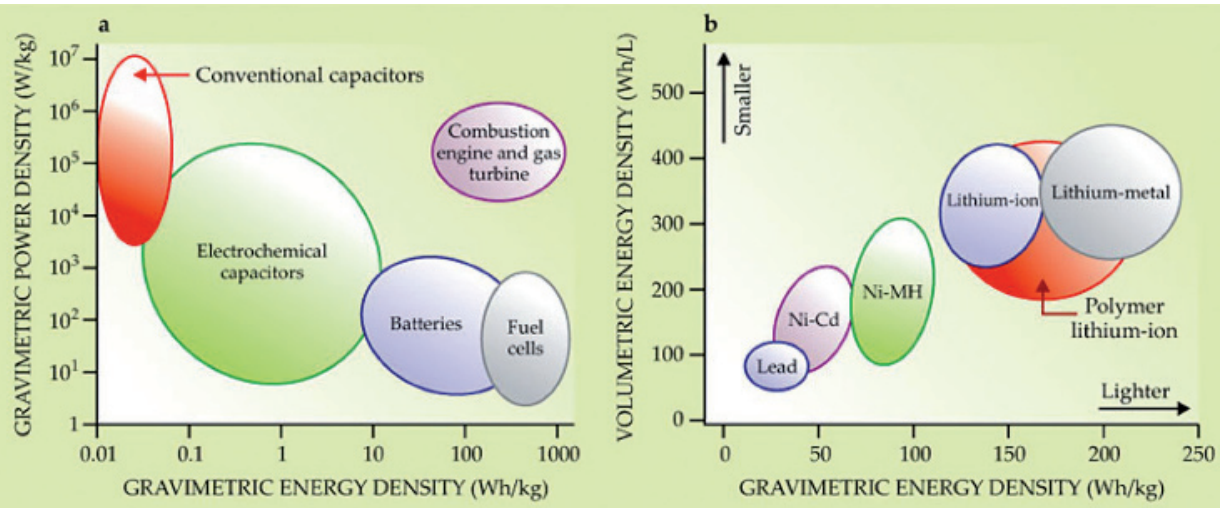

Fig. 8. - Combustion engines have high energy density.

Extremely interesting was the study presented by L.J.F. Hermans and shown in fig. 9, about the transportation energy efficiency, not only related to man made machines, but extended to the whole animal kingdom. Conclusions are that a man riding a bicycle is

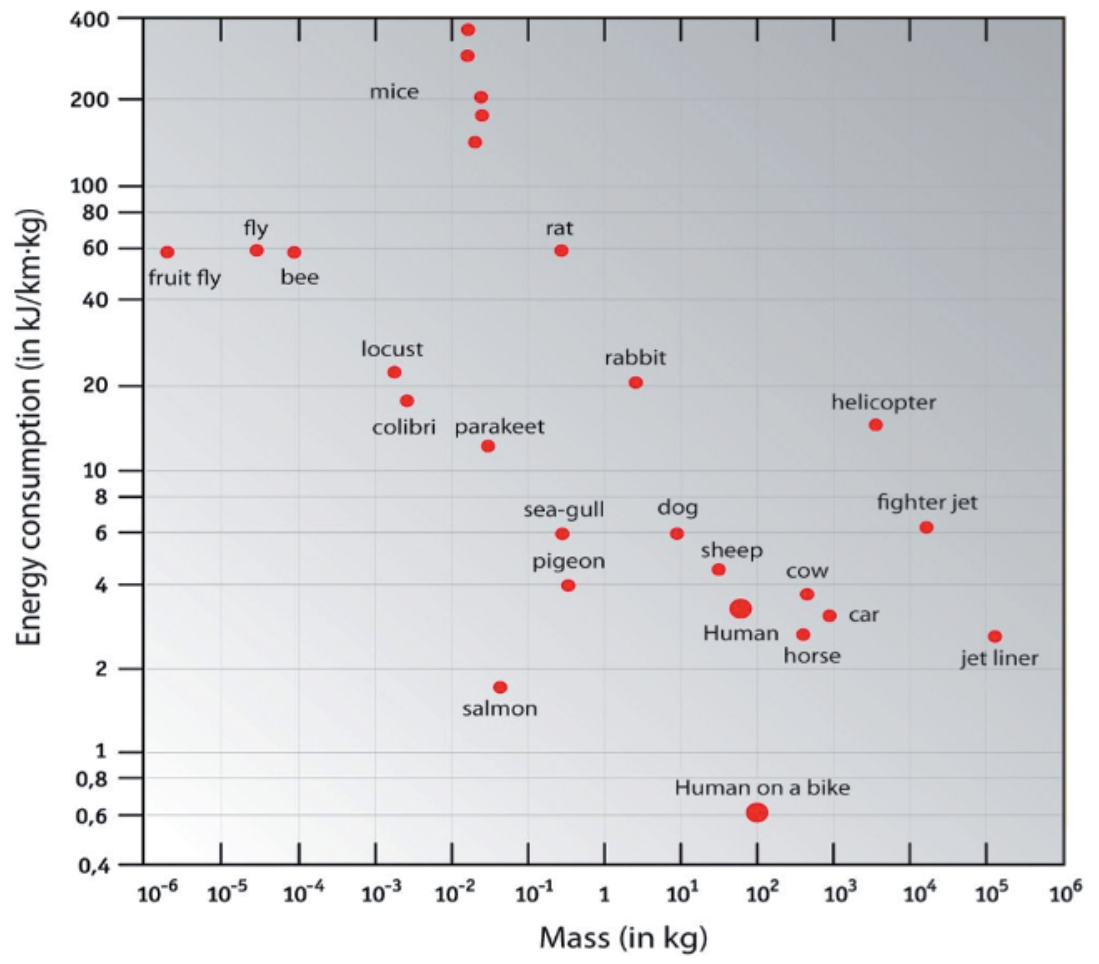

Fig. 9. - Transportation energy consumption: human on a bike beats them all. 


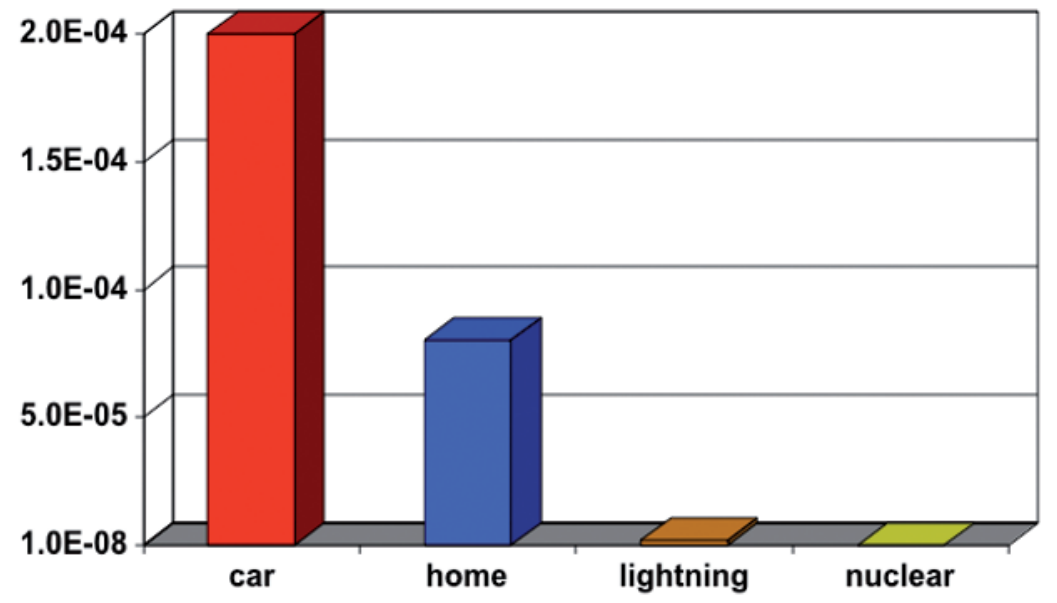

Fig. 10. - Lethal accident risk analysis results (frequency per year).

the most efficient transportation system, followed by the salmon and by the horse: no wonder our ancestors have chosen the horse, being impossible to ride a salmon!

Also nuclear energy may be a sustainable energy source able to contribute to overtake the limits of the actual system. Nuclear energies are certainly not renewable energies but given the high-energy density (6 orders of magnitude more than fossil fuels) and relative abundance of the fuel they exploit, both fission, with breeding reactors, and fusion, with the expected developments, may offer a sustainable alternative for the next thousands of years.

Fundamental developments for these technologies are expected in the next decades: safety and waste management are felt like the most important limits for further fission energy diffusion. Often the perceived risk is quite different from the real risk and E. Ricotti presented results, displayed in fig. 10, showing that the lethal car accident risk is much higher than the equivalent nuclear risk. Despite this evaluation, accidents happen and improving safety standards has always been the driving force of nuclear reactor developments.

Cause and effects of the Fukushima accident have been discussed in detail and, even though modern nuclear plants are considerably safer than Generation II reactors damaged in Japan, the accident analysis may still contribute to improve nuclear safety. The IAEA (International Atomic Energy Agency) International Fact-Finding Mission found out that, despite a commendable dedication of the operators:

- the tsunami risk was underestimated,

- there have been deficiencies in the command-control chain and in the rules/organization of the responsibilities and control.

After safety, the second limitation for a broader diffusion of fission energy is the 

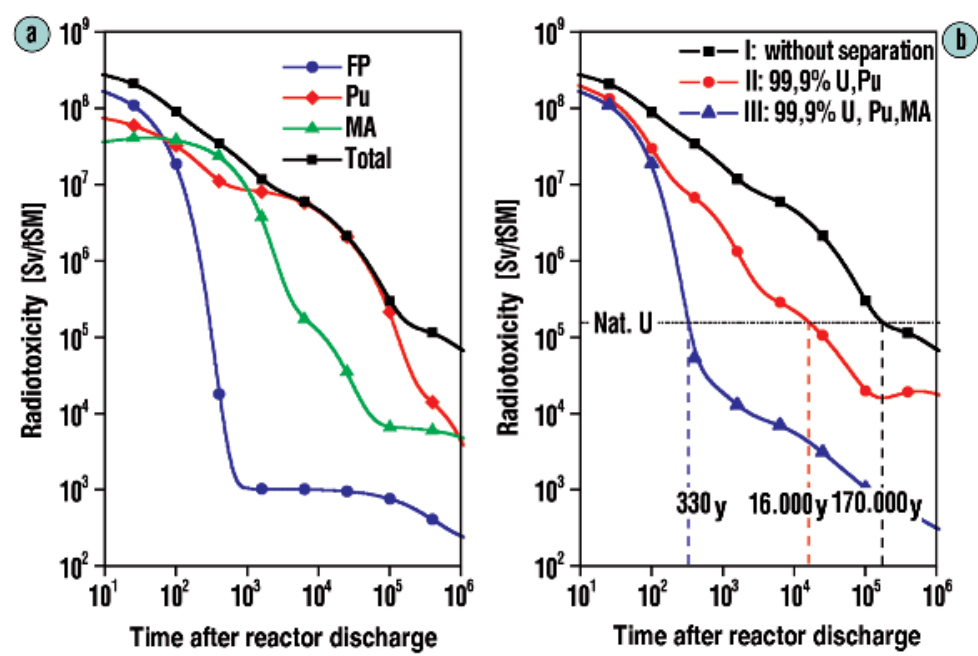

Fig. 11. - Radiotoxicity of $1 \mathrm{t}$ of spent fuel from a pressurized water reactor $\left(4.2 \% \mathrm{U}^{235}\right.$, burn-up $50 \mathrm{GWd} / \mathrm{t}$ ) with regard to ingestion as a function of time after fuel discharge. Reference value: radiotoxicity of the amount of natural uranium that was used to produce $1 \mathrm{t}$ of nuclear fuel. Without partitioning (a); with separation of $99.9 \%$ of $\mathrm{U}$ and $\mathrm{Pu}$, and $\mathrm{U}$ and $\mathrm{Pu}$ and MA (b).

problem of nuclear waste management: as H. Freisleben reminded us in his talk on final disposal of radioactive waste, a geological storage of about 200000 years is needed before nuclear waste radiotoxicity goes back to the equivalent level of the uranium ore used to produce the nuclear fuel that, after being used in a nuclear reactor, produced the waste under consideration. This is a way to evaluate when nuclear waste radiotoxicity can be considered no longer dangerous for the environment; radiotoxicity is determined to its maximum possible level, as if the nuclear waste were ingested.

When uranium and plutonium are extracted from nuclear waste ( $\mathrm{U}^{235}$ and $\mathrm{Pu}$ are then burned in mixed oxide fuel), radiotoxicity goes down to its original level in about 16000 years, as shown in fig. 11, and the mass to be disposed in the storage is only $0.48 \%$ of the original waste mass. Furthermore, if also the minor actinides (MA) are extracted, radiotoxicity goes down to its original level in about three centuries, a much shorter time frame that requires a historical disposal, much easier to handle than the geological one.

Separation of MA however is reasonable only if Generation IV nuclear reactors or accelerator driven systems will be built to burn or transmute MA, making their longterm storage dispensable: once more $\mathrm{R} \& \mathrm{D}$ is very important also in this energy sector.

Meanwhile, most of nuclear waste produced since the beginning of nuclear age, are collected in interim storages: either scientific studies or international agreements have discarded options like disposal in outer space, in subduction zones, at sea or in ice-sheet. At the moment the preferred procedure for high-level waste and long-lived radionuclides, is deep geological disposal at depths between 250 and $1000 \mathrm{~m}$ using a system of natural and engineered barriers (multi-barrier concept). 


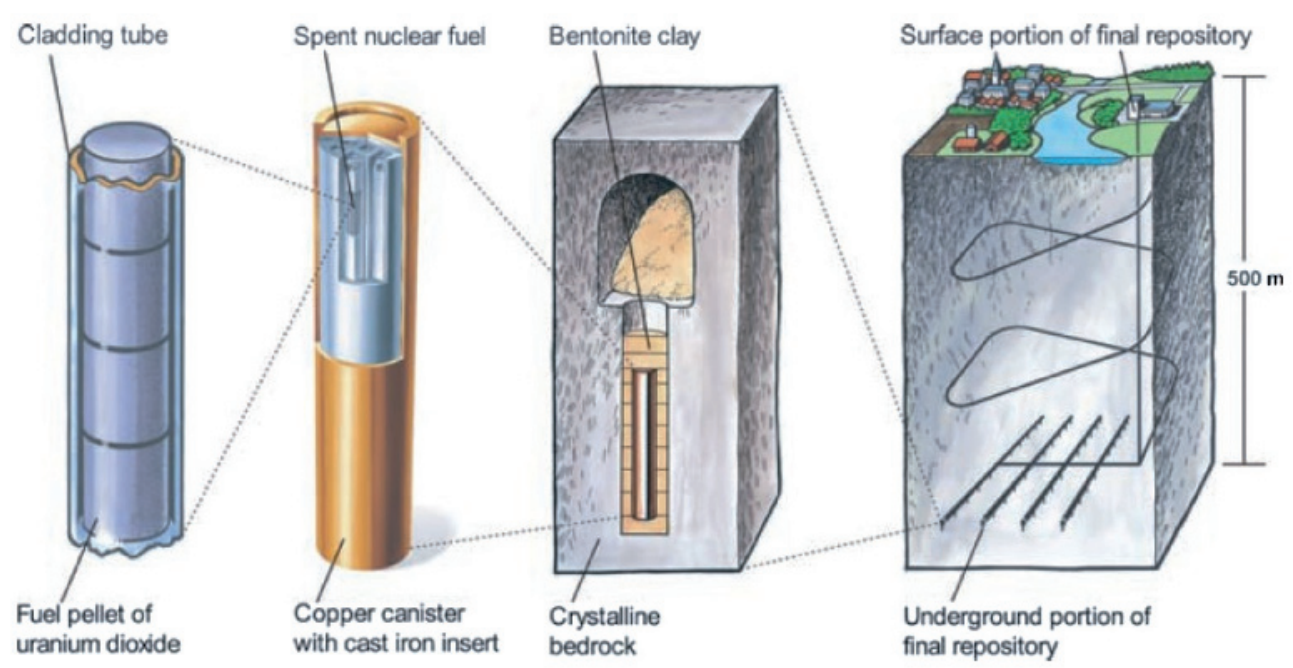

Fig. 12. - The Swedish concept of final waste repository.

Since 1999 a military deposit, Waste Isolation Pilot Plant (WIPP) near Carlsbad, USA, is implemented for trans-uranium waste (TRU) from the US weapons programme; $600 \mathrm{~m}$ thick salt rock, covered by $300 \mathrm{~m}$ rock and soil. The WIPP uses a continuous miner to carve disposal rooms out of the Permian Salt Formation, nearly half a mile below the surface: the Horizontal Emplacement and Retrieval Equipment (HERE) is used to push remote-handled transuranic waste into horizontal boreholes in the disposal room walls.

A civilian storage, illustrated in fig. 12, following the multi-barrier concept for deep geological disposal is going to be implemented by SKB (the Swedish Nuclear Fuel and Waste Management Company).

Magnetic confinement is one of the R\&D strategies to replicate on Earth the fusion energy production that breeds stars and our Sun, as represented in fig. 13.

ITER, as described by F. Wagner in his lectures on fusion by magnetic confinement, is an international collaboration among the most important world players, China, Europe, India, Japan, Korea, Russia, USA, building a fusion prototype reactor near Cadarache in France.

Its major goal is to reach for the first time the break even point, when the output power for the fusion reaction equals the input power, and then go to the ignition point, when the plasma keeps on burning without needing any more energy from external sources.

Next decades are fundamental for fusion energy and following ITER, the goal is to build DEMO, a prototype of a civilian electric energy fusion reactor.

There is a clear road-map to commercialize fusion; of course, there is still no guarantee of final success but research into high temperature plasmas is an intellectually rewarding field. 

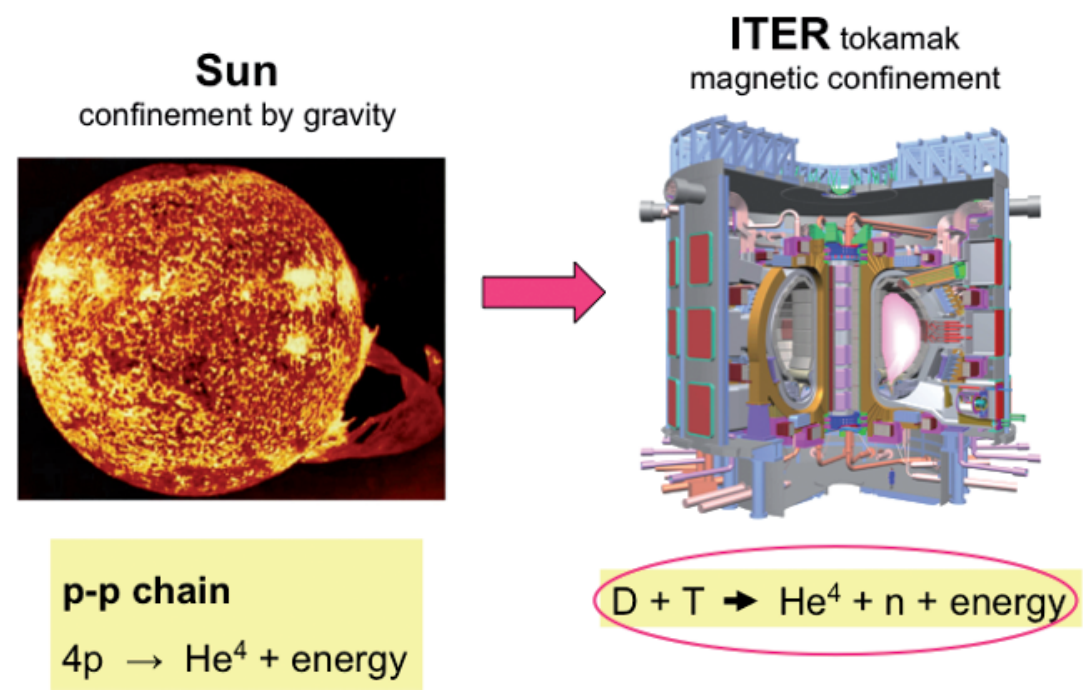

Fig. 13. - Magnetic confinement to replicate the fusion energy that breads our Sun.

Moreover:

- Fusion has a tremendous potential: $0.08 \mathrm{~g} \mathrm{D}$ and $0.2 \mathrm{~g} \mathrm{Li}$ put in a fusion reactor would supply a family of 4 with electricity for a year.

- ITER will answer open physics questions related to burning plasmas.

- ITER and DEMO will move away from plasma science toward a more technological orientation.

- After the ITER physics and technology programme - if successful - fusion could be placed into national energy supply strategies.

- With fusion, a clean, safe and - according to our expectations - economic power source could be handed over to future generation.

Indeed advantages of this kind of energy production would be enormous:

- Energy pay-back time $\sim 6$ months, with an energy amplification factor $>40$.

- Fuel costs can be ignored, taking to a LCOE 6-10 cent/kWh.

- No chain reactions, fundamental physics laws prevent uncontrolled power excursions.

- Radiation dose during normal operation very small.

- Low energy reservoir; no plant destruction in case of loss-of-coolant accident (LOCA). 


\section{Comparison of Carbon Capture processes (brown coal)}

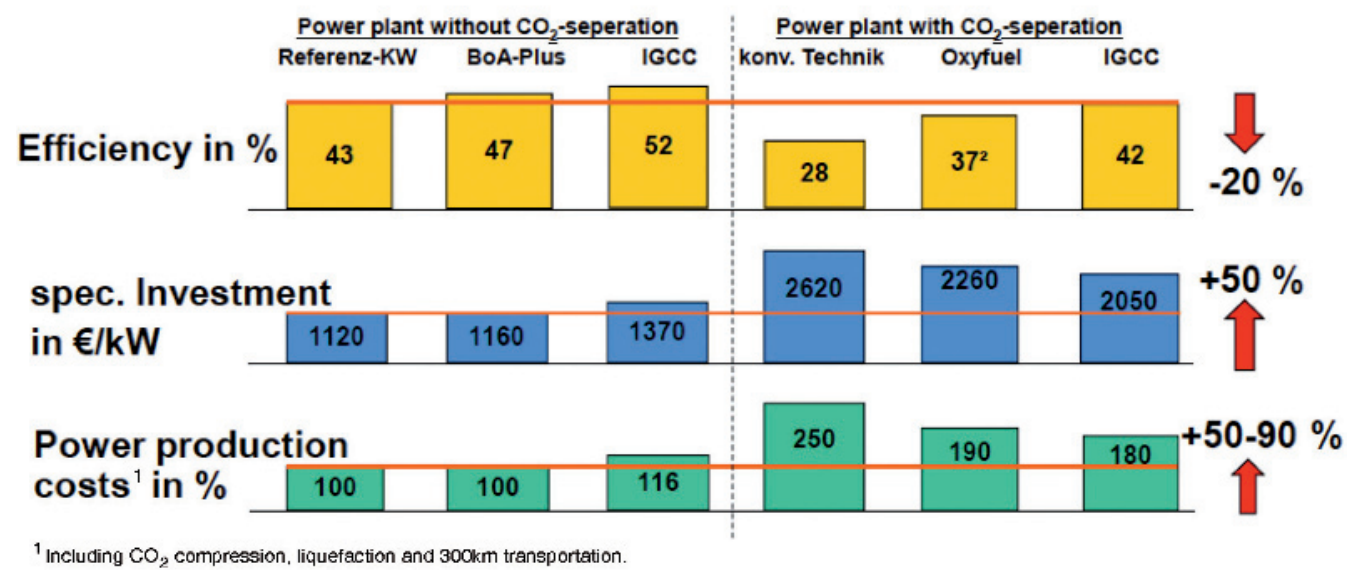

Fig. 14. - CCS increases the investment plant reducing the conversion efficiency: the resulting energy production costs may almost double.

- In case of major accident no evacuation and no exchange of soil necessary.

- No release of environmentally relevant gases and no $\mathrm{CO}_{2}$ external costs.

- Volume of radioactive waste is comparable to that of fission (same power, same lifetime) but about $99 \%$ of the activated material can be recycled and the remaining $1 \%$ has a decay-time $\sim 100$ years.

- Waste does not have to be actively cooled.

- Fusion has low remaining radiotoxicity.

The $\mathrm{CO}_{2}$ concentration reduction in the atmosphere, as illustrated by $\mathrm{H}$. Held in his lectures on climate stabilization, is among the sustainable energy production targets: according to the IPCC (Intergovernmental Panel on Climate Change), fossil fuel combustion will very likely be the major driver of global warming in the 21 st century. Despite the fact that there are still basic scientific open questions, like the climate sensitivity, namely the change in global mean surface temperature for doubling pre-industrial $\mathrm{CO}_{2}$ concentration, a precautionary argument suggests to invest 1-2\% of the GDP (Gross Domestic Product) to try to keep the temperature increase below $2 \mathrm{C}$.

A possible strategy to address this problem is the Carbon Capture and Sequestration (or Storage, CCS). It is clear that, unlike other solutions as renewable or nuclear energies, the only target of this strategy is to reduce $\mathrm{CO}_{2}$ emissions, not to develop a new energy source: indeed a CCS plant would produce less energy at a higher cost than a similar thermoelectric fossil fuel plant without CCS, as clearly shown by M. Gaderer in his lectures on advanced fossil power plants, and summarized in fig. 14. 


\section{Background: Role of Efficiency in $\mathrm{CO}_{2}$ Abatement McKinsey Greenhouse Gas Abatement Cost Curve}

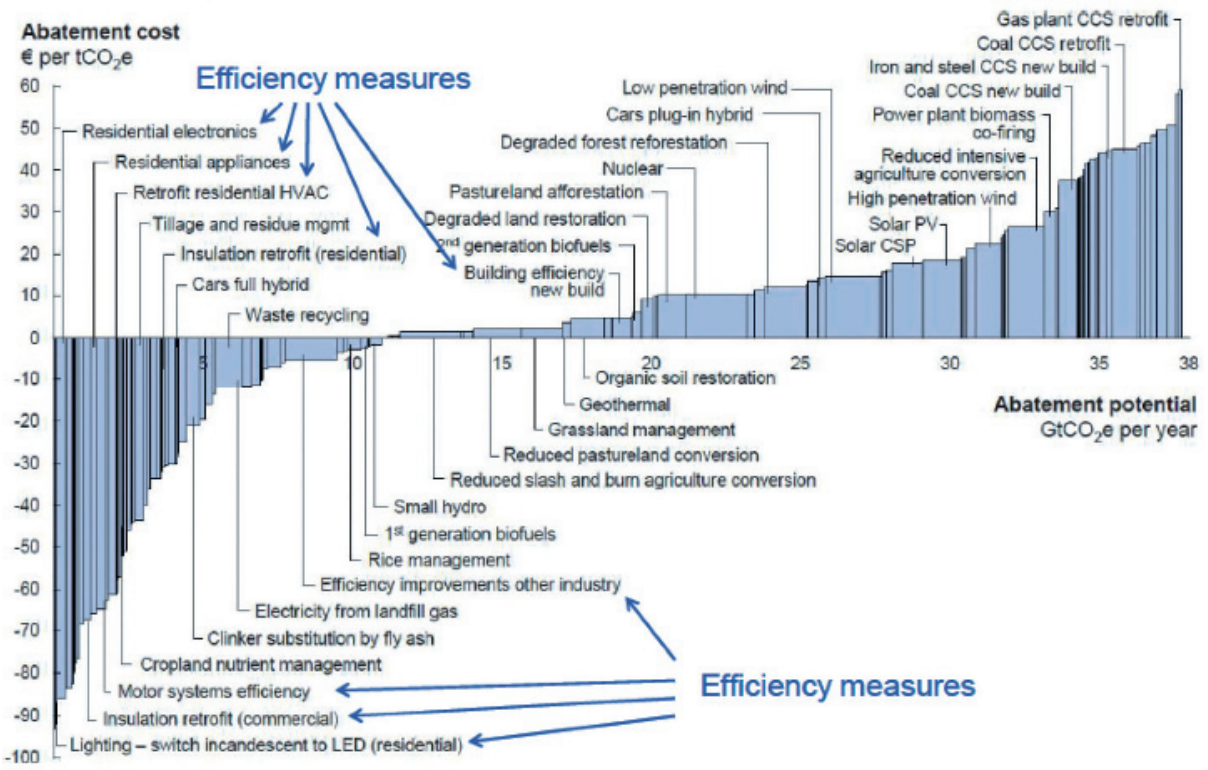

Fig. 15. - Energy efficiency may play an important role in $\mathrm{CO}_{2}$ emission abatement.

Several problems are still unsolved: a stable $\mathrm{CO}_{2}$ storage is a very delicate issue and deep underwater tests or mountain geological basin studies are being done, as shown us by $\mathrm{H}$. Johansen in his lecture on large scale $\mathrm{CO}_{2}$ storage, to find a possible solution.

Nowadays more and more studies show that the best way to reduce emissions using modern but existing technologies is energy efficiency, and often this approach even saves money, as shown us by C. Ohler and seen in fig. 15.

According to the International Energy Agency (IEA), about $76 \%$ of the 2020 emission reduction target would be reachable with a better energy efficiency while just $14 \%$ could be coming from renewable energies.

It is then desirable to produce energy in a sustainable and more respectful way for the environment exploiting at its best any possible solution and energy source, but it is clear that, given the present technology, the most important contribution may come from a better energy efficiency.

Given this consideration, I find that the EPS-SIF Energy School spirit is well represented by fig. 16, coming from a studen's talk.

I would now conclude with the words by E. De Sanctis in the first lecture of the School:

"While the energy challenge is global and fields of R\&D are interdisciplinary and closely interrelated, energy communication is not yet. 


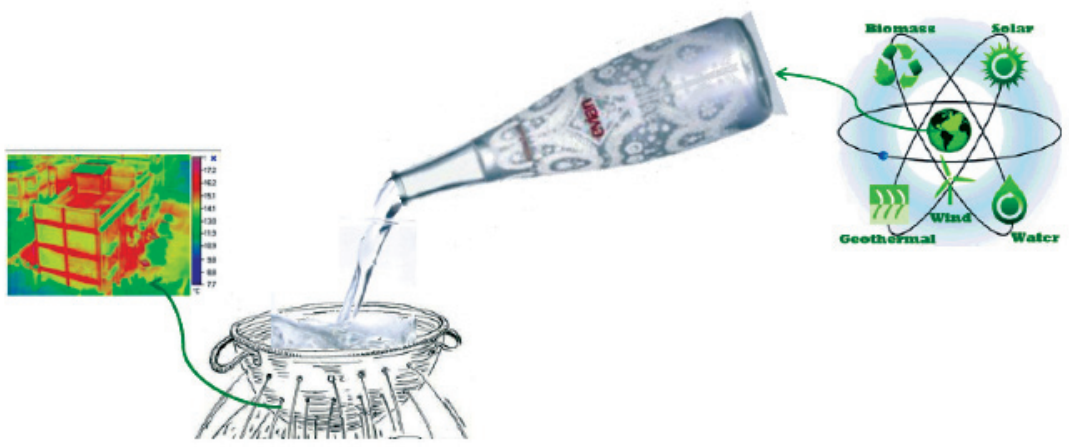

Fig. 16. - Energy challenge: not an easy single solution. Each source has to be exploited at its best without wasting the produced energy.

International and interdisciplinary collaboration in energy communication is needed to better support international research and projects in the energy sector.

- Energy communication is particularly important today, when society is confronted with a number of immediate, urgent problems. The world is facing threats of war for energy supply, the danger of overpopulation and famine, mounting social and racial conflicts, and the destruction of our natural environment.

- An uninformed public is very vulnerable to misleading ideas. Awareness and understanding of scientific ideas and issues by those without training will produce an enhanced ability to sift the plausible from implausible and to make the right decision".

One point that all the speakers agreed on, is that there are no obvious solutions: no single energy carrier or technology will suffice to safeguard our future energy supply. Consequently, researchers must examine a broad range of options and develop many different kinds of technologies.

Only new investments on $R \& D$ can allow to meet the growing demand for energy in a responsible, equitable, and sustainable way.

Password: R\&D 